\title{
Barriers to innovation in services and manufacturing firms: The Case of Kosovo
}

\author{
Betim RETKOCERI, \\ Faculty of Economics, University of Prishtina "Hasan Prishtina", Prishtina, Kosovo \\ betimretkoceri@gmail.com \\ Rinor KURTESHI, \\ Faculty of Economics, University of Prishtina" Hasan Prishtina", Prishtina, Kosovo \\ rkurtesh@hawk.iit.edu
}

\begin{abstract}
The aim of this study is to discover the barriers to innovation in Kosovo service and manufacturing firms. In accordance with the research objectives, this study presents a comparison between service and manufacturing firms regarding barriers to innovation. The study is exploratory and a mixed methodology is used, while the findings are compared with the most recent literature. The findings indicate that traditional management practices and state policies are hindering innovation, although there is a general recognition for change. Additionally, resistance to change and traditional operational practices are found to impede innovation. Lastly, lack of planning skills, lack of financial resources, fear of failure and lack of adoption of an innovation culture are found to be fundamental factors in impeding innovation in Kosovo firms. The contribution of this research is in enriching and extending the current knowledge of barriers to innovation for academia, practitioners and readers. Notably, this is a unique contribution for Kosovar academics and practitioners interested in the main factors that impede innovation.
\end{abstract}

Keywords: Barriers to innovation, innovation, innovation management, Kosovo

JEL Classification: 030, 031, M10.

\section{Introduction}

Global recession and slow economic growth among developed and less developed countries are increasing the need to innovate. Innovation is a fundamental feature of corporations of modern times to increase their activities and retain their competitive advantage and a top priority among CEOs around the world (Sawhney et al., 2006). Innovation is one of the key factors that boosts effectiveness and makes companies more competitive in the global market. Innovation is a factor for making wealth from new products and making them 
wanted (desirable) from costumers (Navickas and Kontautiene, 2012). Evangelista and Vezzani (2012) confirm that innovations have positive impact on employment on both sectors, in services and in manufacturing. According to Muller et al. (2005) innovators are the leaders of every industry.

Moreover, customer behavior is changing and day-by-day expectations from producers and service providers are increasing due to increasing of information means and awareness. So, it is an indispensable need for businesses to innovate in order to decrease their costs, improve their productivity (Baird et al., 2011; Fallah and Lechler, 2008) and remain in the market (Oksanen and Rilla, 2009; Song et al., 2010).

The need to study innovation, especially among EU countries is increasing dramatically. In particular, the focus on innovation barriers is highly increasing. This is becoming one of the hot topics of the EU agenda due to the lag behind US in innovation and high growing firms (Bartelsman, et al., 2005). According to Oke (2004) innovations in services are lagging behind innovations in manufacturing and he argues that knowing barriers of each sector could help explaining the reasons behind this difference. However, we do know very little on how firms in Kosovo are doing in terms of managing innovation and what barriers towards innovation they are facing.

Thus, this paper will make a comparison between barriers to innovation in services and manufacturing firms in Kosovo and will try to find similarities and differences. In this study there will be used both, theoretical and empirical approaches. Since the nature of the study is exploratory, the theoretical part will be covered by general innovation management theories regarding barriers to innovation in services and manufacturing. A relevant literature review and gap identification will explain the importance and significance of studying in this area. Then, a methodology justification, sampling and data analysis will continue toward the end this paper with findings, conclusion and recommendations.

Finally, this study could be interesting for Kosovo practitioners as well as foreign investors interested in investing in Kosovo. Therefore, the importance and originality of this research is that there isn't any study undertaken in order to reveal the barriers towards innovation in Kosovo firms.

The research objectives to achieve understanding and analyzing the query are:

- O1. Discover the impediments of innovation in Kosovo services and manufacturing firms.

- O2. Discover differences between services versus manufacturing sectors regarding barriers to innovation

- O3. Compare the findings with the existing literature. 


\section{Literature review}

\subsection{Definition of Innovation}

All businesses have some sort of competitive advantage, which is related to many dimensions of their business scope, however if these competitive advantages are not maintained and renewed they tend to degrade during the time. Given in other words, the one exceptional thing that can make sustainable competitive advantages thrive is innovation (Morris, 2013).

Companies that foster innovation can maintain better competitive advantage and positioning in the market (Peng at al., 2008; Branzei and Vertinsky, 2006) and according to Charterina and Landeta (2013) innovation is the only way to overcome hyper competition. Additionally, the development of the service industry is increasing the need to understand the process of innovation in a broader manner. Henceforth the interest of researchers is in innovation in service sectors especially considering that the increased service industry is becoming very important in developed countries economies and more important in transition country economies due to the impact of innovation in economic development and job creation (Kuester et al., 2013; Krasniqi, 2009; Michael and Pearce, 2009).

Since the first definition of the term "innovation" from Joseph Schumpeter in 1934 there was generated a considerable amount of "innovation" definitions (Ettlie and Rosenthal, 2011). Recently, Baregheh et al. (2009) were able to collect almost sixty definitions of innovation from the existing literature and came with one of the newest definitions of innovation, which textually says: "Innovation is the multi- stage process whereby organizations transform ideas into new/improved products, service or processes, in order to advance, compete and differentiate themselves successfully in their marketplace" (p. 1334).

Nowadays, innovation is no more defined within the context of high end technology or new products, but it overlaps and it includes a broader aspect of business activities (Navickas and Kontautienè, 2013). According to Gogodze (2013) innovation is a system that creates and utilizes new knowledge. It is a system that strengthens the competitive position of countries and boosts economic growth. 


\subsection{Barriers to innovation}

Many researchers have focused their studies on finding the factors that impede innovation (Hölzl and Janger, 2013; Flynn, 2008). According to D'Este et al. (2012) there are two major types of barriers to innovation and distinguishing between them is a necessity for innovation management and innovation policy. The first type of barriers is described as "revealed barriers" and is related to all factors that undergo innovation processes and learning experience; it is measured by the degree of difficulty that these elements are about to realize. The second type is referred as "deterring barriers" and it is related to the factors that inhibit innovation processes. Therefore, the first type reveals the degree of difficulty of a firm to deal with innovation while the second determines a firms ability to engage on innovation. There are two main perceptions, barriers that make innovation difficult (difficulties) and barriers that inhibit innovation (inability). According to D'Este et al. (2012), the main barriers to innovation are attributed to:

- "Cost factors"

- "Knowledge factors"

- "Market factors"

- "Regulation factors"

\subsubsection{Cost factors}

Cost related factors and financial problems can lead to innovation barriers (Larsen and Lewis, 2007). According to Dabla-Norris et al. (2012) a suitable financial environment may support the increasing of productivity of firms and can simultaneously foster innovation by facilitating technological innovation and low cost production. Reluctance of financing organization to support innovation could have tremendous negative impact on innovation performance.

Beside the high cost of innovation (Baldwin and Lin, 2002) and access to financial resources, there is another barrier within organizations, which is more manageable. This barrier is led by mismanagement of resources or failure to allocate enough resources for innovation, which often harms the process of innovation by not considering or pushing forward the good innovative ideas (Krentz and Clark, 2008). In terms of cost, compared to services, the manufacturing industry faces bigger challenges due to much higher costs for innovation (Sirilli and Evangelista, 1998). According to Madrid- Guijarro (2009) cost related barriers to innovation tend to differ with the size of the organization. Larger firms tend to 
have less cost related barriers but they still do have financial resources problems. In accordance with Madrid-Guijarro (2009), Krentz and Clark (2008) argue that innovation can be hampered by lack of financial resources.

\subsubsection{Knowledge factors}

According to Larsen and Lewis (2007) the lack of skills among knowledge employees are considered as main barriers to innovation. This opinion is in line with Hölzl and Janger (2013) who rank skill barriers as top five barriers to innovation. In the study of D'Este et al. (2012) these skills are related to the knowledge factors that inhibit innovation.

Johnson (2010) concludes that knowledge deficit undermines the capabilities of firms to create right value proposition. Consequently, knowledge deficit will lead to offer-demand mismatch and therefore it risks innovations to succeed. Information on technology is also related to knowledge factor barriers and according to (Baldwin and Lin, 2002) lack of scientific and technical information is one of the main impediments in enabling new technologies and consequently harming innovation.

\subsubsection{Market factors}

According to D'Este et al. (2012) one of the main barriers of innovation are posed by the market factors. Within the market factors they include established competition and uncertainty. Established competition tends to have negative impact on rivals innovation due to the market share and recognition while uncertainty is related to the unexpected future events related to customer behavior or competitor strategic moves. Unfair competition is another emerging barrier that is following innovator firms, and has been proven to be discouraging to engage in innovation (Zhu et al., 2012).

Galia and Legros (2004) claim that another major inhibitor of innovation related to the market factors is the lack of information on markets, which is the main feeder of uncertainty, which according to Hölzl and Janger (2013) uncertainty presents a barrier on itself. Moreover, according to Galia and Legros, (2004) costumers responsiveness is another issue that nurtures uncertainty and consequently makes innovation harder.

Much research has taken place in exploring the acceptance of innovation in the market, although the concept of resistance is more widespread in 
organizations. Gullickson (2009) argues that resistance to change can be managed only with the top management support and appropriate leadership approaches. On the other hand, Sutanto et al. (2008) argue that organizations in order to become more innovative, apart from enabling processes for managing change, they have also to inform employees to lower resistance from customers. Furthermore, Hassan (2008) suggests that innovation can be successful only if customers have enough information about new innovative products or services. In order to mitigate the risk of customer resistance Kleijnen et al. (2009) claim that organizations should pursue risk reduction strategies. In contrast to Hassan (2008), Kleijnen et al. (2009) argues that customers should not be overloaded with information and attention should be paid on what kind of innovation is developed and what strategy should be used.

According to Cornescu and Adam (2013) consumer resistance is one of main barriers to innovation and is responsible for the failure of innovation products in the market.

\subsubsection{Regulation factors}

Innovation as a system is bounded to large extent by rules and regulations, including legislations and other institutional factors. As Galia and Legros (2004) claim excessive regulations can hamper innovation. According to Gann et al. (1998) standards present another unsurpassed factor that can inhibit or give organizations freedom to innovate. Flexible regulation can foster innovation, with exception of high-tech companies were strict standards should be used to meet the standards. However, according to Maxwell (1998) minimum quality standards can have negative effects on innovation especially when they are very strict.

Ramanathan et al. (2010) found that regulations and specifically environmental regulations had positive effect on performance, however the downside of this founding is that such regulations have significant negative impact on innovation. According to Oke (2004) there are also other relevant factors that inhibit innovation, and these are related to the patenting problems, inimitable idea generation and lack of likelihood to multiplicate innovation. 


\section{Methodology}

\subsection{Mixed methods}

Since the field of innovation is still developing and there are a lot of things to be added in order to fill the gaps found in the literature, this area needs further research and the exploratory model of investigation will be one of the most appropriate. Based on the literature, using mixed methods or multiparadigmatic methods (Mangan et al.,2004) can utilize the strengths of both methodologies and can give the researcher more freedom for choosing the approach to best extract what they are looking for and according to (Johnson et al., 2007) mixing methods can provide "the most informative, complete, balanced, and useful research results" (p. 129).

According to Brannen (2005) mixed methodology can be more beneficial in understanding the holistic picture of people views about investigated phenomenon and particularly if interviewing approach is used. This allows going beyond conventional surveys which don't give enough space for broader expression but once more this should not be seen as the only method for research and it depends on the objectives of the study taken. Taking into consideration the literature, a mixed research model by Johnson and Onwuegbuzie (2004) will be used in this research, comprising equal status paradigm within sequential time order.

\subsection{Sample}

In order to achieve better understanding of the barriers to innovation and differences among business sectors in Kosovo, most representative service and manufacturing firms are included into the sample. Due to the potential of innovations, this study is focused on service and manufacturing firms. According to Tether (2005) innovation in services can be studied using the same tools developed for studying innovation management in manufacturing companies.

Due to the lack of available data to make a decision based on the barriers to innovation, this study will take into consideration the size factor to make a decision for the sample choice. To support this decision this study will take into consideration the indications of Sirilli and Evangelista (1998) and Morris (2013) that the larger the firm the more innovative it can be and also the arguments of 
Silvia et al. (2011) and Tether (2005) that the larger the size of the firm the more likely to identify differences between sectors.

Therefore, taking into consideration these indications, this research is going to be focused on medium and large companies in Kosovo.

Table 1. Registered businesses in Kosovo according to number of employees

\begin{tabular}{|l|l|r|r|}
\hline Micro Enterprises & 1 - 9 Employees & 102,070 & $98 \%$ \\
\hline Small Enterprises & 10 - 49 Employees & 1,406 & $1 \%$ \\
\hline Medium Enterprises & 50 - 249 Employees & 221 & $0 \%$ \\
\hline Big Enterprises & 250 - Employees & 58 & $0 \%$ \\
\hline & & 103,755 & $100 \%$ \\
\hline
\end{tabular}

Source: www.smesupport.biz-KBRA, 2014

\subsubsection{Sample Structure and Size}

The structure of the sample includes medium and large firms in Kosovo within two major sectors, services and manufacturing. Both sectors are taken as a whole in the study.

Due to the time and resource limitation, the questionnaire is distributed to almost $37 \%$ of the total population. Since the nature of the study is not confirmatory, a smaller number would also be acceptable and in this case the contacted number of participants amounts 102. Regarding the qualitative part, 4 interviews are carried in accordance to the criteria's set in order to achieve equity between the sectors.

Table 2. Participation of businesses according to activities

\begin{tabular}{|l|l|}
\hline Activities & Distribution \\
\hline Mining & $1 \%$ \\
\hline Industry & $11 \%$ \\
\hline Productions, distribution of elektricity, gas and water & $0 \%$ \\
\hline Construction & $6 \%$ \\
\hline Wholesale and retail trade, repair of vehicles and household equipment & $48 \%$ \\
\hline Hotel and restaurants & $8 \%$ \\
\hline Transport, post and telekommunations & $8 \%$ \\
\hline Businesses services & $10 \%$ \\
\hline Other services & $8 \%$ \\
\hline TOTAL & $\mathbf{1 0 0 \%}$ \\
\hline
\end{tabular}

Source: esk.rks-gov.net, 2014 


\subsubsection{Targeted personnel and geographic sample}

For both, quantitative and qualitative assessment, the targeted personnel are managers related or directly involved in the process of innovation management. Creswell (2005) suggests that in exploratory studies the same individuals could be sampled for both data collection methods, therefore regarding qualitative analysis, interviewees are top-managers, general managers, R\&D managers or financial managers. This study is conducted in Kosovo.

\subsection{Draft of data collection questioning routes}

In order to satisfy the research objectives of this study, there are used two research instruments designed to collect primary data. In principle, there is a structured survey questionnaire and an open-ended questionnaire for interviews.

\subsubsection{Quantitative Research Instrument}

The quantitative instrument is developed based on the research instrument used by Ozgen and Olcer (2007) in their research about Innovation Management in Turkish firms. This was the most appropriate one since it is related directly with the aim of the study and research objectives. Some minor changes have been made in order to adapt for specific purposes of this research.

Main sections of the quantitative questionnaire include:

- Screening section - in order to ensure that the questionnaire meets our target sample criteria and these questions are marked as $S$ questions within the first page of the questionnaire.

- Demographics and organization structure - general information for the participant and his/her organization marked as $D$ questions and comprise the following page of the questionnaire.

- Questions that will cover barriers to innovation, which are designed specifically to satisfy objective $\mathrm{O} 1$ and $\mathrm{O} 2$.

\subsubsection{Qualitative Research Instrument}

The qualitative component of research instrument is an open-ended questionnaire related to the topic and main objectives. The qualitative research instrument is derived from the original questionnaire used for quantitative data 
collection although important changes and enhancements have been made. The interview section or qualitative research questionnaire is comprised of five questions related to the barriers to innovation in Kosovo firms.

\subsection{Sampling procedure and data collection}

Due to the limited information and public data availability, random sampling for quantitative analysis was unlikely; therefore the sample is based on convenient factors (contact details), judgment factors (size and sector) and snowball sampling strategy (networks) to find participants.

The data for all medium and large companies based on the employee number was obtained from Tax Administration of Kosovo (TAK). The whole list was divided into two main groups representing two major sectors of companies within manufacturing and services. These data included the name of the company, tax details, number of employees and their physical addresses however it didn't include telephone numbers or e-mail addresses. This created a major limitation and after a detailed search on the Kosova Business Registration Agency (KBRA) database some telephone numbers and e-mail addresses were found. This has served as the basis for creating the final list of companies that were contacted to solicit their participation in the survey. The list of companies does not represent a random selection and it cannot be claimed as unbiased, however it represents the most successful and well-known companies of Kosovo manufacturing and services sector.

\subsection{Data analysis method}

Since there are two types of data collected by quantitative and qualitative means, accordingly, there will be used software to facilitate the process of analysis. In analyzing the collected data, SPSS software was used for quantitative data analysis while ATLAS.ti software was used for qualitative data analysis. Based on the methodological path, data analysis will be focused in comparing both types of data consequently where quantitative analysis will offer statistical view and it will be more explanatory bounded while the qualitative analysis will provide more exploratory understating of the topic under research. 


\section{Research Findings \\ 4.1. General findings}

\subsubsection{Sample size and composition}

The total number of sample population according to statistical data was 279 firms. Total questionnaires distributed were 102 from which filled and valid are 86 , bringing the response rate up to $84 \%$ and the sample size up to $31 \%$ of the total population. All filled questionnaires were completed successfully and none of questionnaires was rejected.

Table 3. Sample size and response rate

\begin{tabular}{|l|r|r|}
\hline Total number of Medium and Large Firms & 279 & $100 \%$ \\
\hline Distributed questionnaires & 102 & $37 \%$ \\
\hline Valid questionnaires & 86 & $31 \%$ \\
\hline Response rate & & $84 \%$ \\
\hline
\end{tabular}

Source: Authors, 2014

Regarding the composition of the sample, $60.5 \%$ of surveyed companies where services while manufacturing firms involved constitute $39.5 \%$ of total population. Based on the company size, the majority of firms are midsize companies (83.7\%) from 50 to 249 employees while $16.3 \%$ are large companies with over 250 employees.

\subsubsection{Demographics and participant characteristics}

Almost half of the sample (50\%) is between 25 to 35 years while roughly $80 \%$ are under 45 years. The distribution based on gender shows significant discrepancy between male (85\%) and female (15\%).

Figure 1. Age of participants

Figure 2. Gender of participants

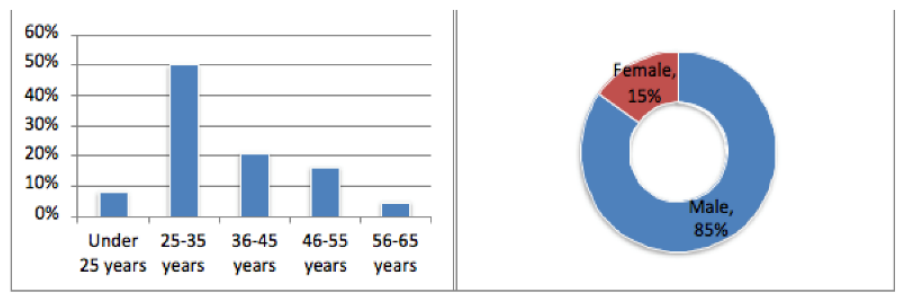

Source: Authors, 2014 
Analyzing the education variable, more than half of managers have masters degree while only $2 \%$ have PhD. However, in sum, $57 \%$ of participants are highly educated.

Figure 3. Participants position within organization

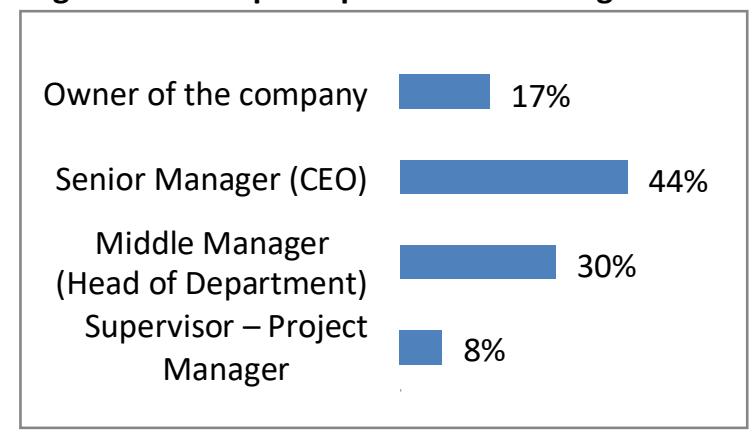

Source: Authors, 2014

The sample is divided in four main groups based on the position of participants within their organizations. The majority of the sample includes Senior Managers and Heads of Departments while $18 \%$ are owners of their companies and only $8 \%$ are Supervisors or Project Managers.

\subsection{Barriers to innovation}

Findings suggest that one of the most influential factors inhibiting innovation in Kosovo is state policies and legislature (56.6\%). Another highlighted barrier is the perception of innovations as a difficult process (56.4\%). This is related to the fear of the unpredictability of future (54.6\%), which has shown to be on top of the barriers in the country level, indicating lack of planning skills to forecast and plan ahead market turbulences.

Traditional operational practices including short term focus and lack of funding have shown significant negative effect on innovation and this barrier is related to fear of failure and the perception that innovation is difficult to be achieved. These barriers have shown significant correlations to each other, which constantly impede innovation (detailed correlations can be found in Appendix A). 
Table 4. Barriers to innovation in Kosovo

\begin{tabular}{|l|r|}
\hline Barrier to innovation & Mean \\
\hline Legislature (existence or lack thereof) is a barrier to innovation & 2.83 \\
\hline Adaptation of novelties is difficult & 2.82 \\
\hline Fear of the unpredictability of future & 2.73 \\
\hline Traditional operational practices & 2.7 \\
\hline Fear of innovation failure (takes long time, costly, difficult) & 2.69 \\
\hline There is a lack of resources & 2.63 \\
\hline Traditional management practices & 2.56 \\
\hline Individual behaviour & 2.53 \\
\hline The group behaviour & 2.08 \\
\hline There is no motivation to innovate & 2.01 \\
\hline $\begin{array}{l}\text { Organization is not supportive of innovation, risk taking and lacks } \\
\text { communication }\end{array}$ & 1.97 \\
\hline
\end{tabular}

Source: Authors, 2014

Qualitative data supports quantitative findings regarding barriers to innovation, however there are some additional insights.

A significant problem according to managers is operational efficiency and particularly related to speed of processes as interviewee P2 states: "The main problems are related to time given to perform our job. " According to interviewee P2 this comes mainly because customers lack information about products and also the basic principles of the production process, leading in misunderstanding and dissatisfaction. This finding discovers another barriers to innovation, especially regarding the diffusion phase of innovations into the market, which in this case is related to customer resistance and awareness about new products and services. According to interviewee P1 "... resistance from the clients and also the consumer conscience about new products and their benefits is one of the main barriers to diffuse ideas successfully into the market". Additionally, interviewee P2 argues that: "Other problems are related to the market need and value recognition" while interviewee P3 has almost the same opinion, "Our main problems derives from buyers mindset and preferences." 
Figure 4. Barriers to innovation (Qualitative analysis)

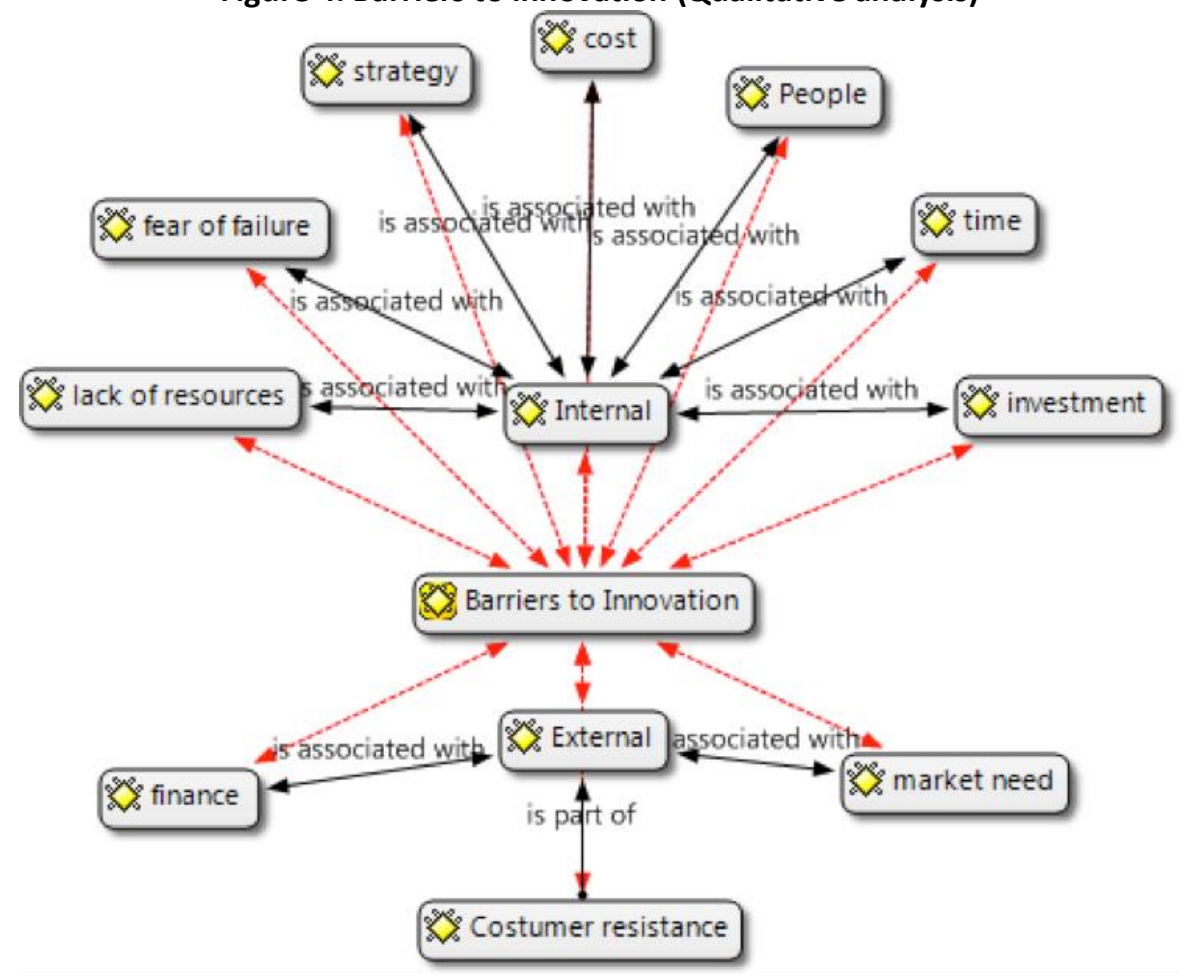

Source: Authors, 2014

Running correlations between barriers, the results show that perception of adapting novelties as difficult has strong positive correlation with uncertainty and fear of innovation failure, what are one of the main barriers to innovation according to findings. Perception of novelties as difficult is also significantly correlated to organizational support, which has shown significant correlation toward motivation, resources and group behavior. Summarizing findings regarding barriers to innovation, in addition to quantitative analysis there is also identified another major problem that follows Kosovo firms and that is customer resistance (or readiness to accept new products/services).

In sum, top barriers of innovation found by both methodologies include but are not limited to:

- State policies and lack of legislature,

- Perception of adaptation of novelties as difficult,

- Fear of the unpredictability of future,

- Traditional operational practices, 
- Fear of innovation failure and

- Customer resistance.

Other factors found are still important to keep in mind although they are not highly ranked they appear to have strong correlations to top barriers summarized here.

Figure 5. Barriers to diffusion (Qualitative analysis)

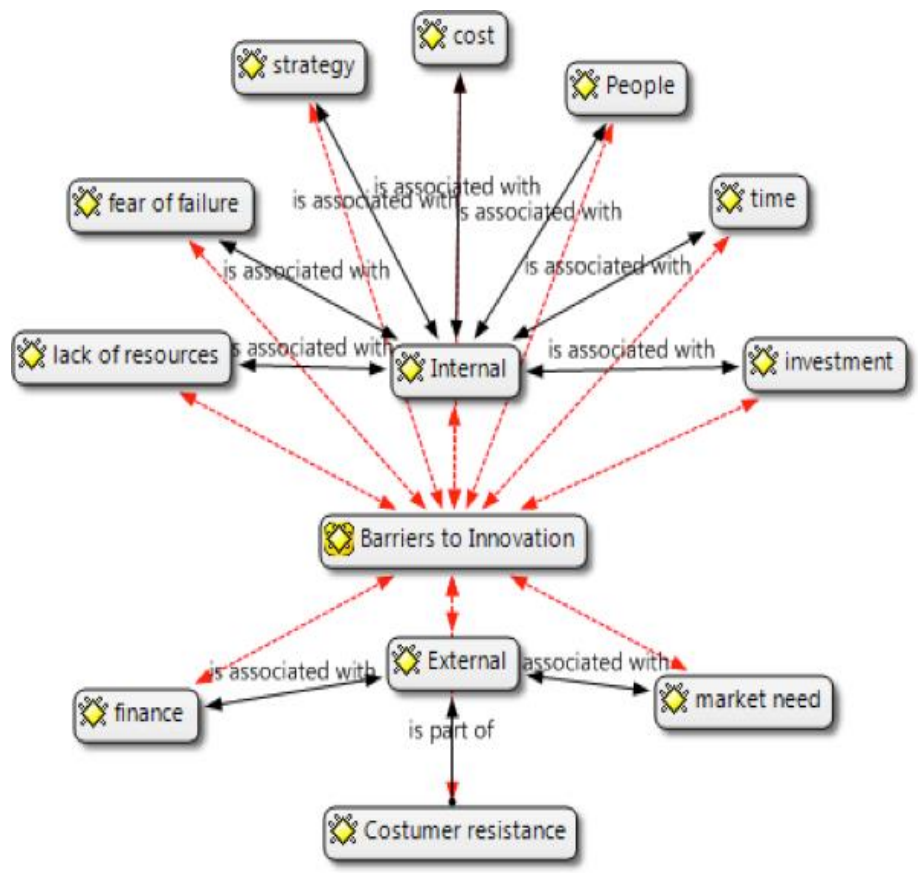

Source: Authors, 2014

\subsection{Differences between barriers to innovation}

Looking at the differences into barriers to innovation within different sectors, there can be noticed that there are statistically significant differences when it comes to the fear of failure and fear of unpredictable future (uncertainty), which are characteristics of the manufacturing sector. On the other hand data analysis suggest that in general most barriers to innovation for each sector have more similarities than differences although the ranking may differ. 
Table 5. Differences between barriers to innovation

\begin{tabular}{|c|c|c|}
\hline Barriers to innovation & Services & Manufacturing \\
\hline State policies and legislature & 2.81 & 3.06 \\
\hline Adaptation of novelties is difficult & 2.75 & 3.06 \\
\hline Traditional operational practices & 2.73 & 2.94 \\
\hline There is a lack of resources & 2.6 & 2.68 \\
\hline Traditional management practices & 2.6 & 2.85 \\
\hline Fear of the unpredictability of future & 2.52 & 2.65 \\
\hline Individual behaviour & 2.46 & 2.65 \\
\hline Fear of innovation failure & 2.44 & (1) \\
\hline The group behaviour & 2.13 & 2.12 \\
\hline There is no motivation to innovate & 1.96 & 2.09 \\
\hline Organization is not supportive of innovation & 1.87 & $\mathrm{O}$ \\
\hline
\end{tabular}

Source: Authors, 2014

\section{Discussion, and Conclusions}

Based on data analysis, government policies and legislature are amongst the main barriers to innovation in medium and large companies in Kosovo. Though ranked in lower positions in relation to other barriers in the literature, it was found to be the most significant factor to inhibit innovation. This finding is in accordance with claims of Blind (2012), Dolfsma and Seo (2013) and Liu et al. (2011) who state that policies and legislation have powerful impact in preventing companies to engage and be successful in innovations.

Another major problem in fostering innovation is related to the perception of innovation as difficult and unachievable. This mindset has shown association with resistance to change and traditional operational practices, whereas both factors inhibit innovation. Perception of innovation as unachievable is also in relationship with the organizational culture. Particularly, an organizational innovation culture argued by many researchers (Chesbrough, 2010; Rosenbuscha et al., 2011; Sharifirad and Ataei, 2012) is still neglected in Kosovo companies.

In addition, traditional operational practices including short-term focus and lack of funding for innovation have shown to be among the main barriers to innovation in the researched sample. Combining bad practices of financial management and limited financial resources (Zhu et al. 2012) creates serious problems for Kosovo firms, including solvency problems. Moreover, lack of dedicated funds for innovation objectives as argued by (Krentz and Clark, 2008) are absent in Kosovo firms. 
Another major barrier to innovation is lack of planning skills. Unquestionably, this is one of the most expressed barriers to innovation in this research sample especially from the qualitative part. Lack of planning skills nurtures another barrier, which is fear of failure. Fear of failure is created due to the lack of information from the market (Galia and Legros, 2004) and lack of skills for suitable planning. This is undoubtedly related to traditional practices of operations, which have shown a considerable negative effect on innovation. Fear of failure has been found to be one of the main barriers of diffusing ideas among researched firms. This indicates a contra opportunistic mindset of managers and lack of market information as argued by Galia and Legros (2004) and Hölzl and Janger (2013).

In addition to the quantitative analysis, it was identified that customer resistance or responsiveness toward novelties can hamper innovation. According to data analysis, customer resistance to new products and services is a major inhibitor of innovation in Kosovo firms. This supports the arguments of Sutanto et al. (2008) and Kleijnen et al. (2009) that customer responsiveness toward innovations is one of the biggest challenges for managers. Thus, it is an indispensable need to develop strategies to overcome this barrier. One solution argued by Hassan (2008) is to give enough information toward customers and this increases the importance of the marketing role in innovation dissemination.

Nevertheless, human resources, with low education and lack of knowledge, have been found to be a barrier in diffusing innovation. Therefore, employee skills should be considered seriously before engaging in innovation activities.

Regarding the difference among service and manufacturing firms, both face similar challenges when it comes to barriers to innovation. However, there is a significant difference when it comes to fear of an unpredictable future and fear of failure, which barriers are more expressed among manufacturing companies and mainly because of the rigidity of the process and hard output adaptation. While, in services, the output of innovation is in constant change and it can be adapted way quicker than in production processes, though it faces three significant challenges as follows: sustainability, standardization and substantiality.

Conclusion: The most important barriers to innovation in Kosovo firm are state policies and legislature, which have shown strong correlation to lack of motivation, fear of failure and uncertainty. In addition, overall state conditions are interlinked with lack of resources, what altogether appears to be the main barriers to innovation in Kosovo firms. Moreover, perception of innovation as a difficult 
process has shown to be the top barrier, mainly due to the traditional thinking and old operational practices which permanently feed resistance to change. Another major problem in fostering innovation drawn from qualitative analysis is attributed to customer resistance to change and lack of innovation strategies. Customer resistance underpins troubles that most companies are facing in marketing and also the lack of planning skills among employees, which ultimately reflects on innovation strategies.

Regarding barriers to innovation among services and manufacturing firms, both sectors share almost the same belief about barriers to innovation, with a slight difference in perception of fear of failure and uncertainty, which is more expressed in manufacturing firms. In addition to that, fears of failure and uncertainty have shown strong correlations with lack of motivation, resistance to change and overall organizational support.

\section{Recommendations}

The barriers to innovation discovered indicate that problems should be addressed and tackled externally by government and internally within firms. Due to the most expressed barrier to innovation in Kosovo, the first recommendation goes to governmental institutions. Legislation and state policies should be tackled by governmental mechanisms, including proactive actions and changes in policies and legislation in favor of organizations in order to foster innovation.

Additional recommendations are addressed toward firm managers mainly since innovation fells under their scope of responsibility. Due to the lack of employee skills and the need for new knowledge, it is an indispensable need to invest in people (Bornay-Barrachina et al., 2012) and create mechanisms to manage knowledge strategically (López-Nicolás and Meroño-Cerdán, 2011) and increase communication means to share it within companies.

Top management involvement is crucial in creating supportive environment by ensuring enough resources and motivating employees. In addition, top management (Gullickson, 2009) should try to encourage and support an innovation culture in order to mitigate the risk of innovation failure (MadridGuijarro, et al., 2009). Moreover, in order to overcome fear of failure companies must increase research on markets to reduce uncertainty (Hölzl and Janger, 2013). This is also linked with customer resistance and readiness, which is one of the main barriers to innovation, and presents an indication of marketing problems that have to be assessed and appropriately adjusted. Of great importance would be utilizing 
the information technology especially in communication to overcome these barriers.

Another important area where managers should seek change is operations management. Traditional operational practices have appeared to be among the main barriers to innovation, therefore managers should be more open minded and engage on new modern operational practices. Moreover, in order to boost the innovativeness level, it is essential to create networks of innovations (Drejer and Jørgensen, 2005) and simultaneously try to empower employees and increase the level of trust.

\section{References}

[1] Baird, K., Hu, K.J. and Reeve,R. (2011). The relationships between organizational culture, total quality management practices and operational performance. International Journal of Operations \& Production Management, 31 (7), $789-814$.

[2] Baldwin, J. and Lin, Z. (2002). Impediments to advanced technology adoption for Canadian manufacturers. Research Policy, 31 (1),.1-18.

[3] Baregheh, A., Rowley, J. and Sambrook, S. (2009). Towards a multidisciplinary definition of innovation. Management Decision, 47 (8), 1323 - 1339.

[4] Bartelsman, E., Scarpetta,S. and Schivardi, F. (2005). Comparative analysis of firm demographics and survival: evidence from micro-level sources in OECD countries. Industrial and corporate change, 14(3), 365-391.

[5] Blind, K. (2012). The influence of regulations on innovation: A quantitative assessment for OECD countries. Research policy, 41(2), 391-400.

[6] Bornay-Barrachina, M., De la Rosa-Navarro, D., López-Cabrales, A. and Valle-Cabrera, R. (2012). Employment Relationships and Firm Innovation: The Double Role of Human Capital. British Journal Of Management, 23 (2), 223-240.

[7] Brannen, J. (2005). Mixing Methods: The Entry of Qualitative and Quantitative Approaches into the Research Process. International Journal Of Social Research Methodology, 8 (3), 173-184.

[8] Branzei, O., Vertinsky, I. (2006). Strategic pathways to product innovation capabilities in SMEs. Journal of Business Venturing, 21(1), 75-105.

[9] Charterina, J. and Landeta, J. (2013). Effects of Knowledge-sharing Routines and Dyad- based Investments on Company Innovation and Performance: An Empirical Study of Spanish Manufacturing Companies. International Journal of Management, 30 (1), 20-39.

[1] Chesbrough, H. (2010). Business Model Innovation: Opportunities and Barriers. Long Range Planning, 43 (2-3), 354-363.

[2] Cornescu, V. and Adam, C. (2013). The Consumer Resistance Behavior Towards Innovation. Economics and Finance, 6, 457-465.

[3] D’Estea, P., lammarino, S., Savona, M. and von Tunzelmann, N. (2012). What hampers innovation? Revealed barriers versus deterring barriers. Research Policy, 41(2), 482-488.

[4] Dabla-Norris, E., Kersting, E. and Verdier, G. (2012). Firm Productivity, Innovation, and Financial Development. Southern Economic Journal, 79 (2), 422-449. 
[5] Dolfsma, W. and Seo, D. (2013). Government policy and technological innovation-a suggested typology. Technovation, 33(6-7), 173-179.

[6] Drejer, I., and Jørgensen, B. H. (2005). The dynamic creation of knowledge: Analysing publicprivate collaborations. Technovation, 25(2), 83-94.

[7] Ettlie, J. E. and Rosenthal, S. R. (2011). Service versus Manufacturing Innovation. Journal of Product Innovation Management, 28 (2), 285-299.

[8] Evangelista, R. and Vezzani, A. (2012). The impact of technological and organizational innovations on employment in European firms. Industrial \& Corporate Change, 21 (4), 871-899.

[9] Fallah, M. and Lechler, T. (2008). Global innovation performance: Strategic challenges for multinational corporations. Journal of Engineering \& Technology Management, 25(1), 58- 74.

[10] Flynn, S. (2008). Managing the Process of Innovation. Research Starters Business, 8(1),.1- 13.

[11] Galia, F. and Legros, D. (2004). Complementarities Between Obstacles to Innovation: Evidence From France. Research Policy, 33, 1185-1199.

[12] Gann, D., Wang, Y., and Hawkins, R. (1998). Do regulations encourage innovation? - the case of energy efficiency in housing. Building Research \& Information, 26 (5), 280-296.

[13] Gogodze, J. (2013). Measuring Innovative Capacities of the Georgia Regions. Journal of technology management \& innovation, 8 (3), 116-129.

[14] Gullickson, B. (2009.) Working with Resistance. Strategic Finance, 90(8), 9-10

[15] Hassan, S. (2008). Bringing Lead-User Innovations to the Market: Research and Management Implications. SAM Advanced Management Journal, 73(4), $51-58$

[16] Hölzl, W. and Janger, J. (2013). Does the analysis of innovation barriers perceived by high growth firms provide information on innovation policy priorities? Technological forecasting and social change, 80(8), 1450-1468.

[17] Johnson, M. (2010). Barriers to innovation adoption: a study of e-markets. Industrial Management \& Data Systems, 110 (2), 157 - 174.

[18] KAS. (2012). Regjistri Statistikor i Bizneseve. Retrieved from: http://esk.rks-gov.net/regjistristatistikor-i-bizneseve/tabelat

[19] Kleijnen, M., Lee, N. and Wetzels, M. (2009). An exploration of consumer resistance to innovation and its antecedents. Journal of economic psychology, 30(3), 344-357.

[20] Krasniqi, B. A. (2009). Personal, household and business environmental determinants of entrepreneurship. Journal of Small Business and Enterprise Development, 16, (1), 146-166.

[21] Krentz, S. and Clark, C. (2008). Strategic Resource Allocation. Trustee, 61(8), 28-30

[22] Kuester, S., Schuhmacher, M.C. and Gast, B. (2013). Sectoral Heterogeneity in New Service Development: An Exploratory Study of Service Types and Success Factors. Journal of Product Innovation Management, 30 (3), 533-544.

[23] Larsen, P. and Lewis, A. (2007). How Award-Winning SMEs Manage the Barriers to Innovation. Creativity \& Innovation Management, 16 (2), 142-151.

[24] Liu, F.C., Simon, D.F., Sun, Y.T. and Cao, C. (2011). China's innovation policies: Evolution, institutional structure, and trajectory. Research Policy, 40 (7), 917-931.

[25] López-Nicolás, C. and Meroño-Cerdán, Á.L. (2011). Strategic knowledge management, innovation and performance. International journal of information management, 31 (6), 502- 509.

[26] Madrid-Guijarro, A., Garcia, D., and Van Auken, H. (2009). Barriers to Innovation among Spanish Manufacturing SMEs. Journal Of Small Business Management, 47 (4), 465-488.

[27] Mangan, J., Lalwani, C. and Gardner,B. (2004). Combining quantitative and qualitative methodologies in logistics research. International journal of physical distribution \& logistics management , 34(7), 565 - 578. 
[28] Maxwell, J.W. (1998). Minimum quality standards as a barrier to innovation. Economics letters, 58 (3), p.355-360.

[29] Michael, S. C., and Pearce, J. A. (2009). The need for innovation as a rationale for government involvement in entrepreneurship. Entrepreneurship \& Regional Development, 21, (3), 285-302.

[30] Morris, L. (2013). Three Dimensions of Innovation. International Management Review, 9 (2), 5-10.

[31] Muller A., Välikangas, L. and Merlyn, P. (2005). Metrics for innovation: guidelines for developing a customized suite of innovation metrics. Strategy \& Leadership, 33 (1), 37-45.

[32] Navickas, V. and Kontautienè, R. (2013). The initiatives of corporate social responsibility as sources of innovations. Business: Theory \& Practice, 14 (1), 27-34.

[33] Oke, A. (2004). Barriers to Innovation Management in Service Companies. Journal of Change Management, 4 (1), 31-44.

[34] Oksanen, J., and Rilla, N. (2009). Innovation and Entrepreneurship: New Innovation as source for competitiveness in Finnish SMES. International Journal of Entrepreneurship, 13, 35-48.

[35] Peng, D. X., Schroeder, R. G. and Shah, R. (2008). Linking routines to operations capabilities: A new perspective. Journal of Operations Management, 26 (6), 730-748.

[36] Sawhney, M., Wolcott, R. C. and Arroniz, I. (2006). The 12 different ways for companies to innovate. MIT Sloan Management Review, 47 (3), 74-81.

[37] Sharifirad, M.S. and Ataei, V. (2012). Organizational culture and innovation culture: exploring the relationships between constructs. Leadership \& Organization Development Journal, 33 (5), 494 $-517$.

[38] Sirilli, G. and Evangelista, R. (1998). Technological innovation in services and manufacturing: results from Italian surveys. Research policy, 27(9), 881-899.

[39] Song, Z. L., Di Benedetto, A. C., and Song, M. (2010). Competitive advantages in the first product of new ventures: IEEE Transactions on Engineering Management, 57, (1), 88- 115.

[40] Sutanto, J., Kankanhalli, A., Tay, J., Raman, K. S. and Tan, B. C. (2008). Change Management in Interorganizational Systems for the Public. Journal of Management Information Systems, 25(3), 133-175.

[41] Tether, B. S. (2005). Do Services Innovate (Differently)? Insights from the European Innobarometer Survey. Industry \& Innovation, 12 (2), 153-184.

[42] Zhu, Y, Wittmann, X. and Peng, M.W. (2012). Institution-based barriers to innovation in SMEs in China. Asia Pacific journal of management, 29 (4), 1131-1142. 


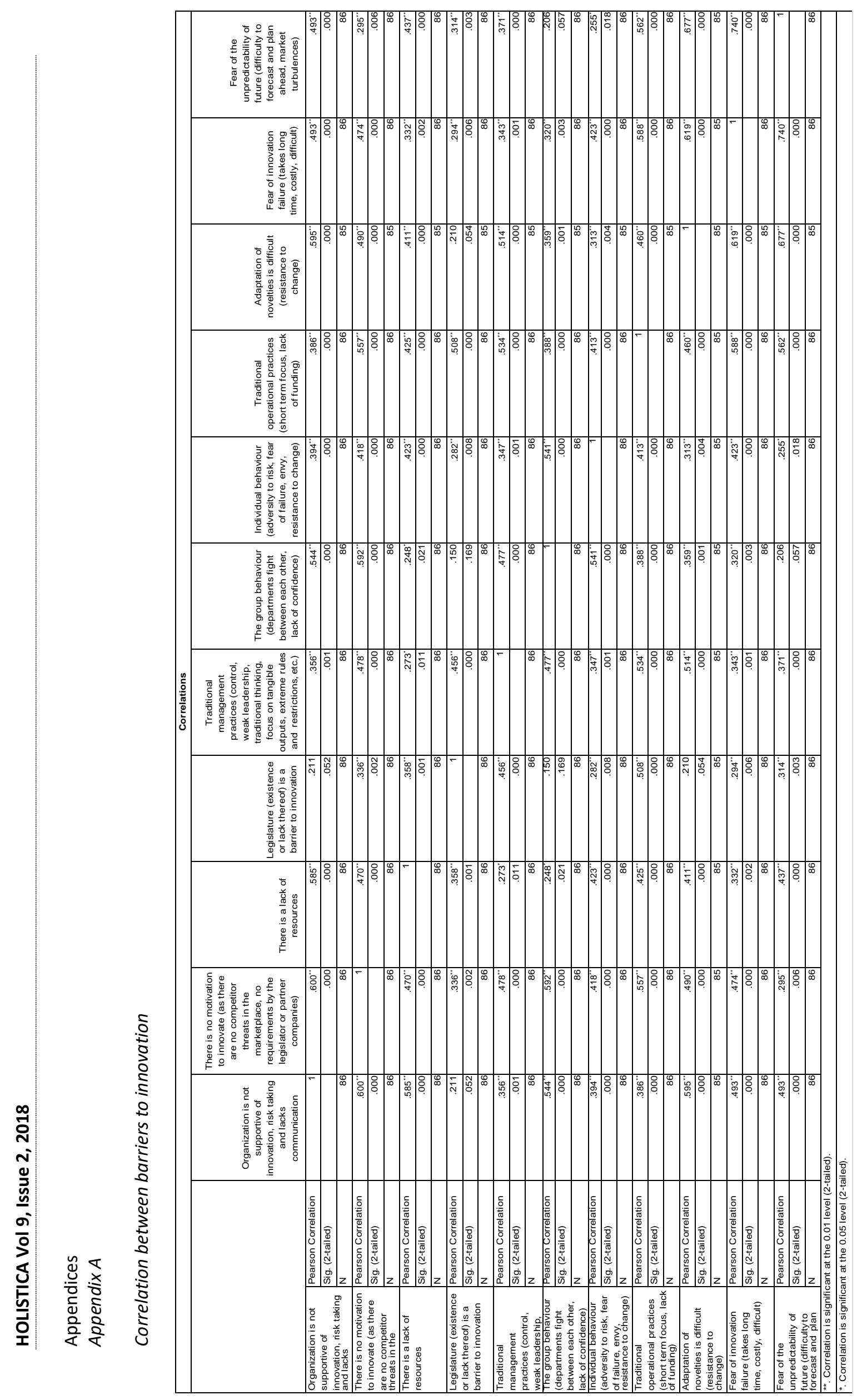

